\title{
Análise da viabilidade técnica da compostagem para produção de adubo orgânico
}

O problema dos resíduos sólidos se deve tanto a alta geração, como a destinação e disposição final ambientalmente inadequada. A compostagem surge como uma forma de aproveitamento capaz de atribuir valor à matéria orgânica que seria disposta em aterros sanitários. Objetivou-se avaliar a viabilidade técnica do processo de compostagem, por meio do monitoramento e avaliação de parâmetros físico-químicos. Neste trabalho, foi montada uma pilha de compostagem sobre o solo, em área aberta, no campus Dom Delgado, UFMA. A mesma foi empilhada com $625 \mathrm{~kg}$ de resíduos, sendo podas do Cajueiro e de Acácia misturadas à cama de frango, em quantidades previamente calculadas de forma a garantir uma boa relação Carbono/Nitrogênio (C/N), em torno de 30:1. Durante o processo foram analisados $\mathrm{pH}$, temperatura, relação $\mathrm{C} / \mathrm{N}$ e Demanda Bioquímica de Oxigênio (DQO), ao final os resultados foram comparados às exigências da Instrução Normativa n.o 25/2009 do Ministério da Agricultura, Pecuária e Abastecimento (MAPA) e da resolução $n^{\circ}$ 481/2017 do Conselho Nacional do Meio Ambiente (CONAMA). A compostagem obteve êxito e todos os parâmetros analisados apresentaram bons resultados. 0 pH se manteve acima de 7,0, finalizando com o valor de 8,6 e os valores de relação $\mathrm{C} / \mathrm{N}$ apresentaram redução de $76,63 \%$ em relação aos valores iniciais. Ao ser comparada com a Instrução Normativa, o composto atendeu às exigências e encaixa-se na classificação de fertilizante orgânico, porém não se manteve na faixa de temperatura de $55 \circ \mathrm{C}$ por 14 dias e 60 ㄷ $\mathrm{C}$ por 3 dias consecutivos respectivamente especificadas pela Resolução do Conama no 481/2017. A pilha atingiu as faixas de temperatura mencionadas pela resolução, porém não se manteve pelo período estabelecido.

Palavras-chave: Resíduos Sólidos; Matéria Orgânica; Fertilizante Orgânico.

\section{Analysis of the technical viability of composting for the production of organic fertilizer}

\begin{abstract}
The solid waste problem is due to the high generation as well as the destination and environmentally inappropriate final disposal. The composting emerges as a form of make use able to attribute value to the organic matter that would be disposed of landfills. The objective was to evaluate the technical viability of the composting process by monitoring and evaluating physical and chemical parameters. In this work, a compost heap was assembled above ground, in open area, at the Dom Delgado campus, UFMA. In this work, it was assembled a compost heap on the ground, in open area, at the Dom Delgado campus, UFMA. It was piled with $625 \mathrm{~kg}$ of waste, being pruning of cashew tree and acacia mixed with chicken manure, in previously calculated quantities to ensure a good Carbon / Nitrogen $(\mathrm{C} / \mathrm{N})$ ratio, around 30:1. During the process, $\mathrm{pH}$, temperature, $\mathrm{C} / \mathrm{N}$ ratio and Biochemical Oxygen Demand (COD) were analyzed. In the end, the results were compared to the requirements of Normative Instruction No. 25/2009 of the Ministry of Agriculture, Livestock and Supply (MAPA) and the Resolution No. 481/2017 of the National Environment Council (CONAMA). The composting was successful and all parameters analyzed showed good results. The pH remained above 7.0, ending at 8.6 and the $\mathrm{C} / \mathrm{N}$ ratio values decreased by $76.63 \%$ when compared to the initial values. When compared to the Normative Instruction, the compound met the requirements and fits the organic fertilizer classification, however it did not remain in the temperature range of 55ㄷ $\mathrm{C}$ for 14 days and 60 으 for 3 consecutive days respectively, specified by Conama Resolution 481/2017. The compost heap has reached the temperature ranges mentioned by the resolution, but has not remained for the set period.
\end{abstract}

Keywords: Solid Waste; Organic Matter; Organic Fertilizer.

Topic: Engenharia Ambiental

Reviewed anonymously in the process of blind peer.

Raíssa Mendes Silva (D)

Universidade Federal do Maranhão, Brasil

http://lattes.cnpq.br/1243681554857052

http://orcid.org/0000-0002-3912-4436

raissamendes.rms@gmail.com

Talita Dantas Pedrosa (iD)

Universidade Federal Rural do Semiárido, Brasil

http://lattes.cnpq.br/0867686471021064

http://orcid.org/0000-0001-8437-7494

talita.pedrosa@ufersa.edu.br

Luciana Kamila Rodrigues Ferreira (iD

Universidade Federal do Ceará, Brasil

http://lattes.cnpq.br/1149485007927997

http://orcid.org/0000-0001-6426-1523

kamilafcoelho@gmail.com

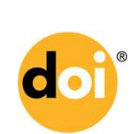

DOI: 10.6008/CBPC2179-6858.2020.002.0020
Received: 05/02/2020

Approved: 11/03/2020

\author{
Thomas Lívio Santos Coelho (iD \\ Instituto Federal do Ceará, Brasil \\ http://lattes.cnpq.br/8162818957607389 \\ http://orcid.org/0000-0002-1151-8783 \\ thomasportal@gmail.com
}

Aline do Vale Figueiredo Barbosa (iD

Universidade Federal do Maranhão, Brasil

http://lattes.cnpq.br/6928015487810508

http://orcid.org/0000-0002-6524-7034

alinefigueiredo @hotmail.com
Referencing this:

SILVA, R. M.; PEDROSA, T. D.; FERREIRA, L. K. R.; COELHO, T. L. S.; BARBOSA, A. V. F.. Análise da viabilidade técnica da compostagem para produção de adubo orgânico. Revista Ibero Americana de Ciências Ambientais, v.11, n.2, p.182-191, 2020. DOI: http://doi.org/10.6008/CBPC2179-6858.2020.002.0020 


\section{INTRODUÇÃO}

Visando solucionar o problema do lixo, foi sancionada em 2010 e regulamentada em dezembro do mesmo ano a Política Nacional de Resíduos Sólidos (lei no 12.305), que reúne o conjunto de diretrizes e ações a serem adotadas objetivando a gestão integrada e o gerenciamento adequado dos resíduos sólidos no Brasil (BRASIL, 2010).

O descarte de resíduos sólidos no Brasil é feito de várias formas, vazadouro a céu aberto, vazadouros em áreas alagadas, aterro controlado, aterros sanitários, usinas de reciclagem, usinas de compostagem, usinas de incineração e outros (IBGE, 2010). Neste sentido, tendo em vista a crescente preocupação com os problemas de poluição do meio ambiente, e ainda associada à escassez de recursos naturais, a compostagem de resíduos torna-se ideal para a estabilização da fração orgânica destes, por meio de processos biológicos controlados que permitam a reciclagem dos nutrientes e a utilização da matéria orgânica.

A compostagem é uma técnica de reciclagem dos resíduos de origem orgânica, onde os mesmos são dispostos em pátios específicos, localizados em unidades denominadas usinas de compostagem, atendendo as condições mínimas (controle de fatores que interferem no processo), na qual haverá a transformação desses resíduos por meio de microrganismos que farão a sua degradação transformando-os em húmus (PEREIRA NETO, 2007). Segundo Pereira Neto (2007), o produto resultante pode ser um adubo ou fertilizante orgânico, que pode melhorar as características físicas, químicas e biológicas do solo, aumentar sua capacidade de retenção de nutrientes e melhorar assim sua fertilidade.

Os resíduos sólidos resultantes de poda geram um volume considerável de material vegetal que pode ser compostado e aproveitado para os mais diversos fins, gerando benefícios ambientais e sociais. Contudo, faz-se necessário levar em consideração na escolha dos materiais para formação de substratos suas características físicas, sua abundância e disponibilidade ao longo do tempo, bem com as suas características químicas, que podem ser corrigidas com práticas de adubação.

No tocante aos resíduos provenientes da exploração avícola, os mesmos se caracterizam pelas carcaças de animais mortos e, principalmente pela cama. Segundo Paganini (2004) e Tessaro (2011) a cama de frango é um material absorvente, que normalmente é distribuído sobre a pavimentação dos galpões que servem de leito às aves, ao final do ciclo produtivo este material será composto ainda por excretas, penas das aves e restos de ração.

À crescente expansão do setor avícola é preocupante, já que ocorre uma maior produção da cama de frango pelo aumento no número de animais alojados. É imprescindível buscar soluções de manejo e de destino do resíduo, a fim de minimizar os impactos por ela causados, principalmente pelas elevadas concentrações de nitrogênio e fósforo presentes no material. Neste sentido, a compostagem se mostra como uma alternativa que viabiliza o tratamento da fração orgânica dos resíduos sólidos, a exemplos da poda de árvores e da cama de frango, agregando valor a estes resíduos e proporcionando sua utilização e aplicação no cultivo de culturas agrícolas. 


\section{MATERIAIS E MÉTODOS}

\section{Localização do experimento}

Este estudo foi conduzido nas dependências da Universidade Federal do Maranhão - UFMA, Campus Dom Delgado, em São Luís, entre os dias 15 de setembro a 29 de novembro de 2018.

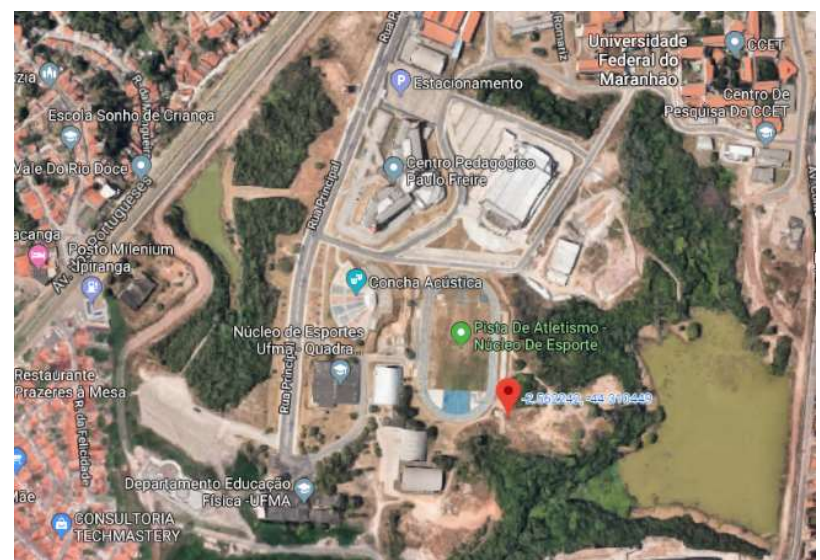

Figura 1: Localização do pátio de compostagem nas dependências da UFMA. Fonte: Google Maps (2019).

\section{Escolha e caracterização da matéria-prima}

Os resíduos utilizados no processo de compostagem foram poda de Acácia e poda do Cajueiro provenientes do próprio campus da UFMA, bem com cama de frango oriunda da empresa Frango Americano localizada em São José de Ribamar, munícipio da Região Metropolitana de São Luís. Estes resíduos foram escolhidos em função da sua disponibilidade, visto que a geração dos mesmos é considerável e que nem sempre possuem uma destinação final ambientalmente adequada. Os resíduos brutos antes de serem incorporados foram caracterizados usando como base para determinação das análises a metodologia da Embrapa (2009). As análises realizadas foram, concentração de nitrogênio total, matéria orgânica (MO), relação $\mathrm{C} / \mathrm{N}$ e umidade.

\section{Preparo e montagem das pilhas de compostagem}

As porcentagens iniciais de cada tipo de resíduo da pilha foram estabelecidas de maneira que possibilitasse obter uma relação $\mathrm{C} / \mathrm{N}$ inicial da mistura em torno de 30:1, valor dentro da faixa recomendada na literatura (PEREIRA NETO, 2007). Utilizou-se a Equação 1 citada por Gomes et al. 2011, para determinar as partes de material rico em carbono, necessárias à montagem da pilha de resíduos.

$$
\mathrm{PMRC}=\frac{\mathrm{MRN}}{\mathrm{MRC}}=\frac{(30 * \% \mathrm{~N})-\% \mathrm{C}}{\% \mathrm{C}-(30 * \% \mathrm{~N})} \quad \text { Equação } 1
$$
MRN - Material rico em nitrogênio MRC - Material rico em carbono

A pilha foi montada com as quantidades apresentadas na Tabela 1 , de modo que ao final da mistura dos resíduos obteve-se uma pilha com relação $\mathrm{C} / \mathrm{N}$ de 34:1. 
Tabela 1: Massa de resíduos em Kg que foram utilizadas para montagem da pilha de compostagem.

\begin{tabular}{|l|l|l|l|}
\hline Parâmetro & Poda de Acácia & Poda do Cajueiro & Cama de Frango \\
\hline Massa & $105 \mathrm{~kg}$ & $110 \mathrm{~kg}$ & $410 \mathrm{~kg}$ \\
\hline Relação C/N & $76: 1$ & $68: 1$ & $16: 1$ \\
\hline
\end{tabular}

Após a trituração dos resíduos com ajuda de uma forrageira, os mesmos foram caracterizados e posteriormente misturados em uma massa total de $625 \mathrm{~kg}$ de resíduos. A pilha foi montada atendendo a altura e ao diâmetro mínimos sugerido por Pereira Neto (2007), de 1,6 m e 1,5 m respectivamente conforme Figura 2.

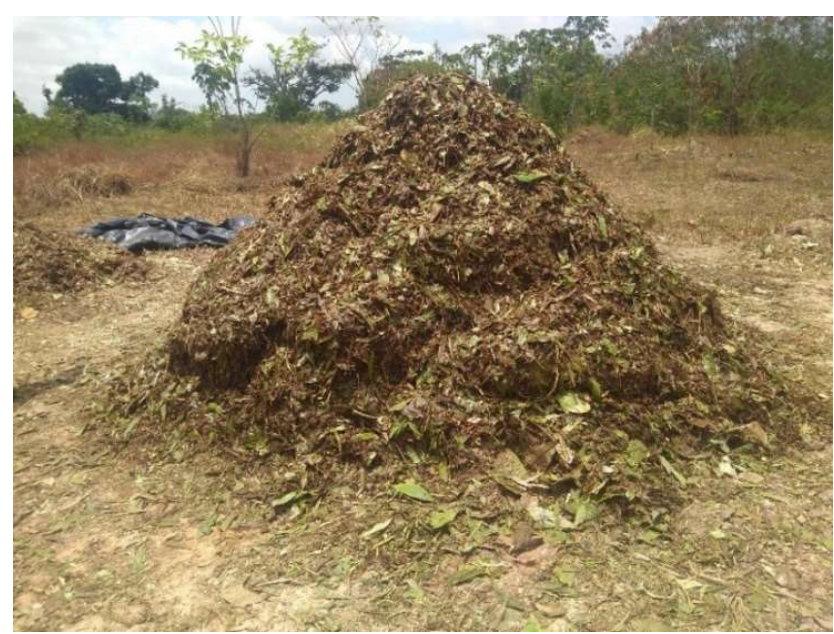

Figura 2. Pilha de compostagem montada com $625 \mathrm{~kg}$.

Neste estudo, o processo de compostagem foi conduzido em superfície com solo plano e não houve a formação de chorume. O reviramento da pilha, para garantir aeração, foi realizado a cada três dias durante os primeiros 60 dias, posteriormente esse intervalo foi alterado para 7 dias. Em cada reviramento foram analisadas as condições de umidade e a mesma foi corrigida a 55\%, considerado valor ideal (PEREIRA NETO, 2007). Antes da correção de umidade eram retiradas amostras para realização de testes em laboratório.

\section{Estudo da Viabilidade Técnica}

Com o intuito de avaliar a viabilidade técnica do processo de compostagem na decomposição controlada dos resíduos, foram monitorados os seguintes parâmetros: temperatura, $\mathrm{pH}$, relação $\mathrm{C} / \mathrm{N}$ e Demanda Bioquímica de Oxigênio (DQO). As amostras foram peneiradas de forma a melhorar sua trabalhabilidade, utilizou-se uma peneira granulométrica de aço inox, com abertura de $600 \mu \mathrm{m}$.

\section{Temperatura}

As medições de temperatura foram efetuadas diariamente, às 8:00 horas, sendo realizadas em três pontos diferentes da pilha (base, meio e topo), utilizando-se um termômetro digital.

\section{Potencial Hidrogeniônico -pH}

$\mathrm{O}$ pH foi monitorado a cada três dias e para a sua determinação utilizou-se a metodologia sugerida por Embrapa (2009), onde, pesou-se 10,0 g de uma amostra in natura retirada da pilha e adicionou-se 50,0 
$\mathrm{ml}$ de solução de cloreto de cálcio $0,01 \mathrm{~mol} / \mathrm{L}$. Essa mistura foi colocada sob agitação por 10 minutos e posteriormente deixada em repouso por 30 minutos. Após esse tempo, foi realizada a determinação.

\section{Carbono Orgânico - CO}

O carbono foi determinado quinzenalmente segundo a metodologia da Embrapa (2009). Para determinar a quantidade de carbono, primeiro quantificou-se a Matéria Orgânica (MO) pelo método da mufla. O teor de matéria orgânica foi determinado em razão da perda de massa do resíduo incinerado, considerando-se o material perdido pela queima no intervalo de variação da temperatura de $65 \stackrel{\circ}{\circ} \mathrm{C}$ a $550{ }^{\circ} \mathrm{C}$, conforme a fórmula:

$$
\mathrm{MO}(\%)=\frac{(A-C)-(I-C) * 100}{(A-C)} \quad \text { (Equação 2) }
$$

A quantidade de carbono orgânico foi obtida pela equação:

$$
\mathrm{CO}(\%)=\frac{M O}{1,72} \quad(\text { Equação } 3)
$$

\section{Nitrogênio Total Kjeldhal}

As quantidades de Nitrogênio foram determinadas por meio da utilização de um destilador de nitrogênio do tipo Kjeldhal, em que o nitrogênio da amostra é transformado em amônio $\left(\mathrm{NH}_{4}\right)$, o qual é posteriormente separado por destilação e finalmente dosado por titulação. Esse método foi dividido em três etapas.

Na primeira etapa foi feita a digestão, onde o nitrogênio orgânico é transformado em amônia e os compostos orgânicos são convertidos em $\mathrm{CO}_{2}$ e $\mathrm{H}_{2} \mathrm{O}$. As análises foram feitas em triplicata, sendo 3 brancos (testemunha) e 3 amostras da pilha. Na segunda etapa é feita a destilação e na terceira e última etapa, as amostras foram tituladas com uma solução de $\mathrm{H}_{2} \mathrm{SO}_{4}$ de normalidade padronizada (0,5 N). Após isso, deve ser feito o seguinte cálculo:

$$
N(\%)=\frac{\text { VAT } * \text { NOR } * 0,999 * 0,014 * 100}{\operatorname{PA}(0,1 \mathrm{~g})} \quad(\text { Equação } 4)
$$

Legenda:

$\mathrm{N}$ - Nitrogênio

VAT - Volume de ácido titulado NOR - Normalidade PA - Peso da amostra

\section{Demanda Química de Oxigênio - DQO}

Para a determinar a DQO, utilizou-se o método da Embrapa (1997). Onde, com base nos valores de CO, obtidos como mostrado anteriormente, fez-se o seguinte cálculo de acordo com Lossin (1971, citado por KIEHL, 1998):

$$
\mathrm{DQO}=26,6 * \mathrm{CO} \quad \text { (Equação 5) }
$$




\section{RESULTADOS E DISCUSSÃO}

\section{Análise da viabilidade técnica}

\section{Temperatura}

O monitoramento da temperatura da pilha foi realizado por um período de 75 dias consecutivos, conforme Figura 3. Foram registradas temperaturas termofílicas no período de 12 a 24 horas após sua montagem, indicando condições satisfatórias de umidade, aeração e nutriente.

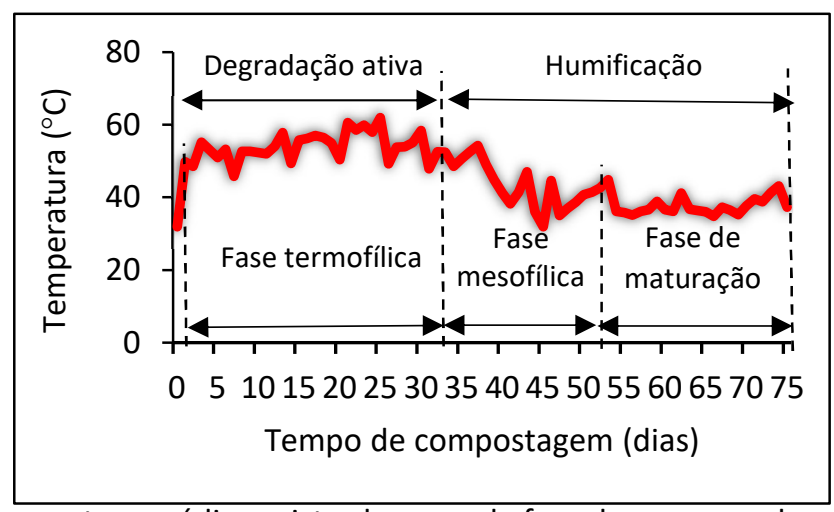

Figura 3: Temperatura média registrada em cada fase do processo de compostagem.

Observa-se que os valores de temperatura registrados na pilha corroboram com os dados obtidos por Pereira Neto (2007), uma vez que em situações satisfatórias de umidade, aeração e nutriente, as pilhas ou leiras devem registrar temperaturas termofílicas no período de 12 a 24 horas após sua montagem. A manutenção da temperatura na faixa termofílica é resultante da intensa degradação da matéria orgânica o qual pode ser considerada de fundamental importância no tratamento dos resíduos, pois é responsável pela diminuição e/ou eliminação dos organismos patogênicos.

Ao analisar o comportamento da temperatura apresentada na Figura 3, observa-se que os primeiros 35 dias de compostagem apresentaram altas temperaturas com pico de $62^{\circ} \mathrm{C}$ no vigésimo quinta dia, onde claramente observa-se um processo de degradação ativa. A partir do trigésimo sétimo dia, houve uma clara redução da temperatura, com atuação de bactérias mesofílicas, até o alcance da fase de maturação.

Heck et al. (2013) avaliaram a influência da temperatura sobre a redução de Escherichia coli, Salmonella sp., ovos de helmintos e vírus entéricos durante o processo de compostagem e obtiveram resultados semelhantes, em que temperaturas termofílicas foram observadas logo após as primeiras 24 horas e se mantiveram até a coleta $6\left(46^{\circ} \mathrm{C}\right)$. Silva et al. (2009) realizando compostagem com esterco de suínos observaram temperaturas máximas de $60^{\circ} \mathrm{C}$ durante a fase termofílica da compostagem, corroborando com os valores obtidos neste trabalho.

Tabela 2: Anexo I da Resolução do Conama no 481/2017.

\begin{tabular}{|l|l|l|}
\hline Parâmetro & Resolução do Conama & Tempo (dias) \\
\hline Temperatura (으) & $>55$ & 14 \\
\hline & $>60$ & 3 \\
\hline
\end{tabular}

Pereira et al. (2013), em estudo de maturação de compostos orgânicos de resíduos agroindustriais 
constataram que as temperaturas médias das pilhas de resíduos orgânicos atingiram a fase termofílica nas primeiras 24 horas, mantendo-se acima desse patamar até o $21^{\circ}$ dia. Contudo, as temperaturas observadas neste trabalho não permaneceram o período de tempo necessário para higienização dos resíduos sólidos orgânicos conforme especificado pela resolução do Conama n 481/2017 apresentada na Tabela 2.

Acredita-se que as precipitações isoladas que ocorreram no início do experimento tenham corroborado com a diminuição da temperatura, embora a pilha tenha sido recoberta com lona durante os episódios de precipitação. Utilizou-se o anexo I da Resolução do Conama no 481/2017, Tabela 2, que específica o período de tempo e temperatura necessários para higienização dos resíduos sólidos orgânicos durante o processo de compostagem.

$\mathrm{Ph}$

O comportamento do $\mathrm{pH}$ ao longo do tempo mostrou-se coerente, uma vez que se manteve alcalino por todo o processo de compostagem, conforme apresentado na Figura 4.

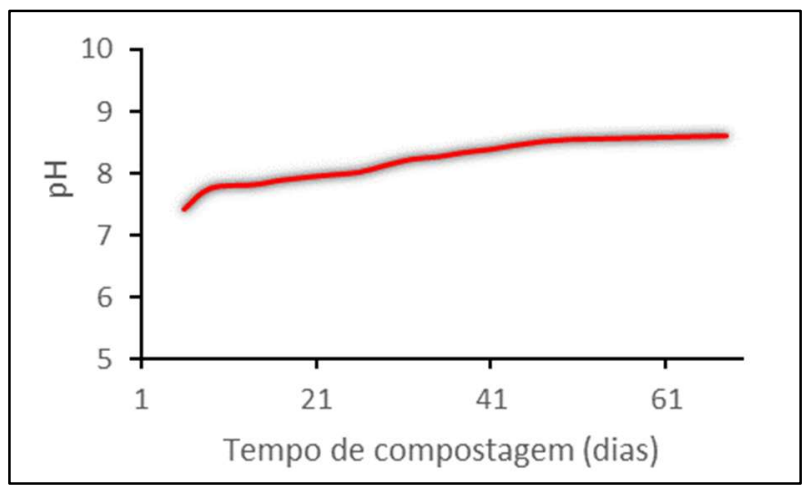

Figura 4: Comportamento do $\mathrm{pH}$ durante os 75 dias de compostagem.

O aumento no valor de pH se dá conforme ocorre a estabilização dos materiais, corroborando com o comportamento observado nesse estudo, em que os menores valores de $\mathrm{pH}$ foram observados logo no início do processo, variando entre 7,41 e 7,75 e posteriormente este parâmetro tem seus valores aumentados para 8,6 no final do processo.

Inicialmente são esperados valores de pH baixos, já que há a quebra das moléculas maiores a moléculas menores, liberando ácidos, que são posteriormente consumidos, elevando o $\mathrm{pH}$ das pilhas (PEDROSA, et al. 2016). Heck et al. (2013), também encontraram valores mais baixos de pH no início do processo e foram se tornando alcalino ao longo do processo de degradação do material orgânico.

Faixas de $\mathrm{pH}$ variando entre 6,0 e 8,0 é seguramente a faixa mais adequado aos microrganismos presentes na compostagem (SANTOS, 2007). Valores de $\mathrm{pH}$ mais alto ao final do processo de compostagem são importantes, pois indica que o composto pode ser usado como corretivo de solo. Os valores de pH para fins de comercialização de fertilizantes orgânicos devem ser maiores que 6,0 segundo a Instrução Normativa número 25 do Ministério da Agricultura, Pecuária e Abastecimento, IN 25 (MAPA). Neste sentido, a pilha avaliada atingiu o valor mínimo exigido. 


\section{Relação C/N}

Os resultados indicam que houve efetiva redução da relação de carbono e nitrogênio, conforme apresentado na Figura 5. Esta relação é um dos mais importantes fatores na determinação do grau de maturação do composto orgânico.

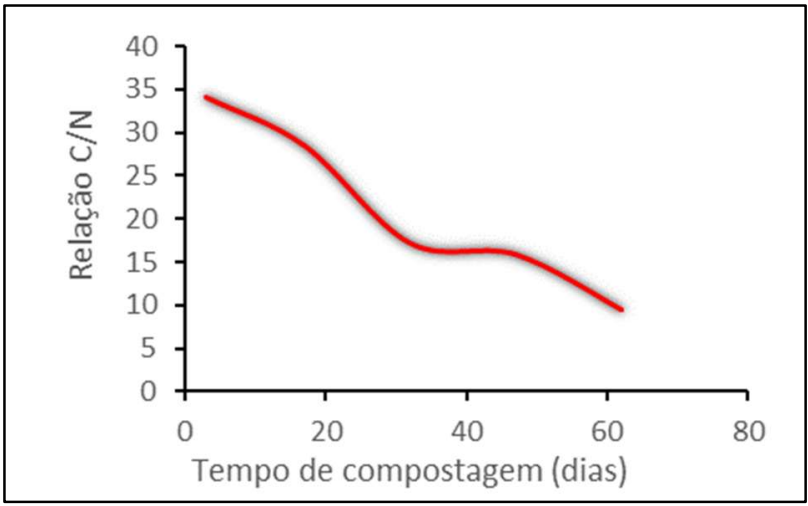

Figura 5: Comportamento da relação $\mathrm{C} / \mathrm{N}$ durante a compostagem.

A redução observada nos valores de relação $\mathrm{C} / \mathrm{N}$ indica que o processo de degradação ocorreu de forma satisfatória. A eficiência de um processo de compostagem é diretamente proporcional à eficiência com que os microrganismos conseguem captar e metabolizar os nutrientes. Os microrganismos necessitam prioritariamente de carbono como fonte de energia para a oxidação metabólica e nitrogênio que é essencial na síntese de proteínas, ácidos nucleicos, aminoácidos, enzimas, entre outros (HERBETS, 2005). Pereira et al. 2013, também observaram baixos valores de relação $\mathrm{C} / \mathrm{N}$ para os compostos finais produzidos em solo exposto e em solo impermeabilizado (pátio).

Baixa relação de $\mathrm{C} / \mathrm{N}$ provavelmente tem ligação com a conversão do carbono orgânico a gás carbônico por todo o processo (QUEIROZ, 2007). O valor de relação $\mathrm{C} / \mathrm{N}$ do composto final atendeu o valor máximo de 20:1 estabelecido pela Instrução Normativa número 25 do Ministério da Agricultura, Pecuária e Abastecimento, IN 25 (MAPA).

\section{Demanda Química de Oxigênio - DQO}

A Figura 6 indica que houve uma redução nos teores de matéria orgânica das amostras, determinadas indiretamente pela DQO durante todo o processo de compostagem com uma redução de aproximadamente $63 \%$.

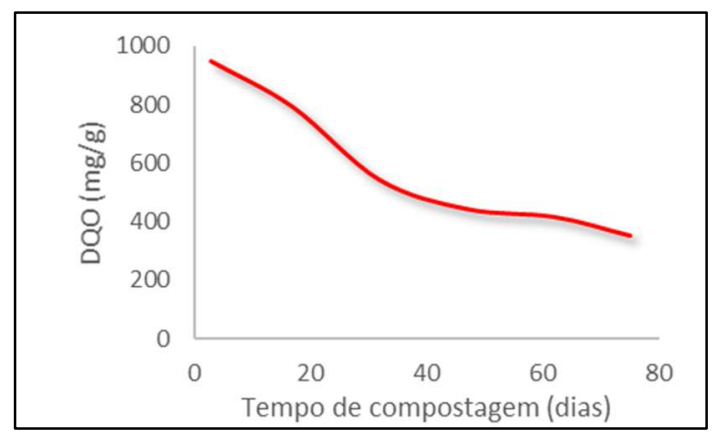

Figura 6: Comportamento da DQO durante o processo de compostagem. 
Quanto a DQO, o composto é considerado cru quando possui uma DQO igual ou maior que $900 \mathrm{mg} / \mathrm{g}$. Quando bioestabilizado deve apresentar uma DQO inferior a $700 \mathrm{mg} / \mathrm{g}$ e no composto tomado como curado em sua totalidade a DQO apresenta-se abaixo de $300 \mathrm{mg} / \mathrm{g}$ (KIEHL, 2002).

Neste sentido, o valor de DQO observado neste estudo aponta que houve bioestabilização e posterior cura do composto produzido. Neste caso, o composto orgânico produzido apresentou valor inferior a 700 $\mathrm{mg} / \mathrm{g}$, portanto é considerado bioestabilizado.

\section{Composto final}

O composto final foi caracterizado quimicamente ao concluir 75 dias de compostagem, onde este apresentava-se de cor escura e sem odores. O composto produzido segundo a Instrução Normativa no 25 de julho de 2009, é classificado como Classe A, com características de fertilizante orgânico que em sua produção utiliza matéria-prima de origem vegetal, animal ou de processamentos da agroindústria, onde não sejam utilizados no processo, metais pesados tóxicos, elementos ou compostos orgânicos sintéticos potencialmente tóxicos, resultando em produto de utilização segura na agricultura.

Sendo assim, o composto final foi comparado às especificações contidas no anexo III da IN supracitada. A Tabela 3 apresenta valores iniciais e finais de parâmetros monitorados durante a condução deste estudo, para fins de comparação do composto produzido com IN no 25/2009 do MAPA, bem como para entendimento da evolução do processo de compostagem no que se refere a sua viabilidade técnica.

Tabela 3: Evolução do teor de umidade, nitrogênio total, carbono orgânico, pH e relação C/N e comparação do composto produzido com IN no 25/2009 do MAPA.

\begin{tabular}{|l|r|r|r|}
\hline Parâmetros & VI & VF & IN \\
\hline TU (\%) & 26,0 & 43,0 & 50,0 (máx.) \\
\hline NT (\%) & 1,05 & 1,95 & 0,5 (mín.) \\
\hline CO (\%) & 35,75 & 15,50 & 15,0 (mín.) \\
\hline pH & 7,41 & 8,60 & 6,0 (mín.) \\
\hline Relação C/N & 34,06 & 7,96 & 20,0 (máx.) \\
\hline
\end{tabular}

Legenda: TU - Teor de umidade; NT - Nitrogênio total; CO - Carbono orgânico; VI - Valor inicial; VF - Valor final; IN Instrução normativa.

Por fim, observa-se que, ao compararmos os valores iniciais e finais dos parâmetros monitorados neste estudo com a instrução normativa $n^{\circ} 25$ do MAPA, observou-se que todos os parâmetros atenderam aos limites máximos e mínimos especificados pela Instrução normativa, demonstrando que a compostagem foi eficiente na transformação da matéria orgânica em fertilizante orgânico.

\section{CONCLUSÕES}

Este trabalho realizou a compostagem de resíduos orgânicos e avaliou sua viabilidade técnica por meio do monitoramento de parâmetros físico-químicos. Os parâmetros monitorados apresentaram bons resultados, indicando que houve o processo de degradação e que foi eficiente para o tratamento dos resíduos orgânicos, o que garante a eficiência técnica do processo de compostagem, alvo de estudo desta pesquisa.

O composto final foi caracterizado e apresentou ótimos valores quando comparados aos valores iniciais. Por meio do monitoramento da temperatura foi possível identificar claramente a fase em que se 
encontrava a compostagem. $\mathrm{O} \mathrm{pH}$ apresentou o aumento esperado de acordo com a literatura. Os valores que apresentaram maior variação foram os de relação C/N e DQO apresentando redução de 76,63\% e $63,19 \%$, respectivamente, mostrando o quanto foi eficiente e significativa a degradação durante os 75 dias de compostagem.

Ao ser comparado com a instrução normativa do MAPA, o composto final se mostrou dentro de todas as exigências, podendo assim ser definido como fertilizante orgânico composto, classe A. Porém, ao ser comparado com a Resolução do Conama no 481/2017 o mesmo não se manteve na faixa de temperatura de $55^{\circ} \mathrm{C}$ por 14 dias e $60^{\circ} \mathrm{C}$ por 3 dias consecutivos respectivamente. Ressalta-se que a pilha atingiu as faixas de temperatura mencionadas pela resolução, porém não se manteve pelo período estabelecido.

\section{REFERÊNCIAS}

BRASIL. Instrução Normativa SDA no 25, de 23 de Julho de 2009. Ministério da Agricultura Pecuária e Abastecimento. Brasília: DOU, 2009.

BRASIL. Ministério do Meio Ambiente. Resolução CONAMA № 481, de 03 de outubro de 2017. Estabelece critérios e procedimentos para garantir o controle e a qualidade ambiental do processo de compostagem de resíduos orgânicos, e dá outras providências. Brasília: DOU, 2017.

BRASIL. Política Nacional de Resíduos Sólidos. Lei no 12.305. Brasília: Congresso Nacional, 2010

EMBRAPA. Empresa Brasileira de Pesquisa Agropecuária. Manual de análises químicas de solos, plantas e fertilizantes. 2 ed. Brasília: Embrapa Informação Tecnológica, 2009

EMBRAPA. Empresa Brasileira de Pesquisa Agropecuária. Preparo de composto orgânico na pequena propriedade rural. Petrolina: Instruções técnicas da Embrapa semiárido, 2009.

HECK, K.; MARCO, E. D.; HAHN, A. B. B.; KLUGE, M.; SPILKi. F. R.; VAN DER SAND, S. T.. Temperatura de degradação de resíduos em processo de compostagem e qualidade microbiológica do composto final. Revista Brasileira de Engenharia Agrícola e Ambiental, v.17, n.1, p.54-59, 2013.

HERBETS, R. A.; COELHO, R. C. A.; MILETTI, L. C.; MENDONÇA, M. M.. Compostagem de resíduos sólidos orgânicos: aspectos biotecnológicos. Revista Saúde e Ambiente, v.6, n.1, 2005.

IBGE. Instituto Brasileiro de Geografia e Estatística. Pesquisa Nacional de Saneamento Básico 2008. Rio de Janeiro: IBGE, 2010.
PAGANINI, J. F.. Produção de frangos de corte. In: MENDES, A.; NAAS, I. A.; MACARI, M.. Manejo da cama. Campinas: FACTA, 2004. p.107-116.

KIEHL, E. J.. Fertilizantes orgânicos. São Paulo: Agronômica Ceres, 1998.

KIEHL, E. J.. Manual de Compostagem: Maturação e qualidade do Composto. Piracicaba: 2002

PEDROSA, T. D.; ASCOLI, C. A.; VIOLA, M.; PAIXÃO, G. C.; REIS, V. P.; AMARAL, A. G.; REZENDE, F. A.; SCHNEIDER, R. M.. Ciclagem de nutrientes por meio da transformação de resíduos em fertilizante orgânico. Nativa, Sinop, v.4, n.1, p.19-24, 2016

PEREIRA NETO, J. T.. Manual de compostagem: processo de baixo custo. Viçosa: Universidade federal de Viçosa, 2007.

PEREIRA, R. A.; FARIAS, C. A. S.; PEDROSA, T. D.; FARIAS, E. T. R.. Maturação de compostos orgânicos de resíduos agroindustriais. Revista Verde, v. 8, n.1, p.264-268, 2013.

QUEIROZ, F. F.. Avaliação do aproveitamento de resíduos vegetais por meio da compostagem em leiras revolvidas: Estudo de caso de Londrina. Dissertação (Mestrado) Universidade Estadual de Londrina, Campus Universitário, 2007.

SANTOS, J. L. D.. Caracterização físico-química e biológica em diferentes laboratórios de produtos obtidos a partir da compostagem de resíduos orgânicos biodegradáveis. Dissertação (Mestrado em Ecologia Aplicada) - Faculdade de Ciências da Universidade do Porto, Porto, 2007.

TESSARO, A. A.. Potencial energético da cama de aviário produzida na região sudoeste do Paraná utilizada como substrato para a produção de biogás. Dissertação (Mestrado em Desenvolvimento de Tecnologia) - Instituto de Tecnologia para o Desenvolvimento, Curitiba, 2011.

A CBPC - Companhia Brasileira de Produção Científica (CNPJ: 11.221.422/0001-03) detém os direitos materiais desta publicação. Os direitos referem-se à publicação do trabalho em qualquer parte do mundo, incluindo os direitos às renovações, expansões e disseminações da contribuição, bem como outros direitos subsidiários. Todos os trabalhos publicados eletronicamente poderão posteriormente ser publicados em coletâneas impressas sob coordenação da Sustenere Publishing, da Companhia Brasileira de Produção Científica e seus parceiros autorizados. Os (as) autores (as) preservam os direitos autorais, mas não têm permissão para a publicação da contribuição em outro meio, impresso ou digital, em português ou em tradução. 